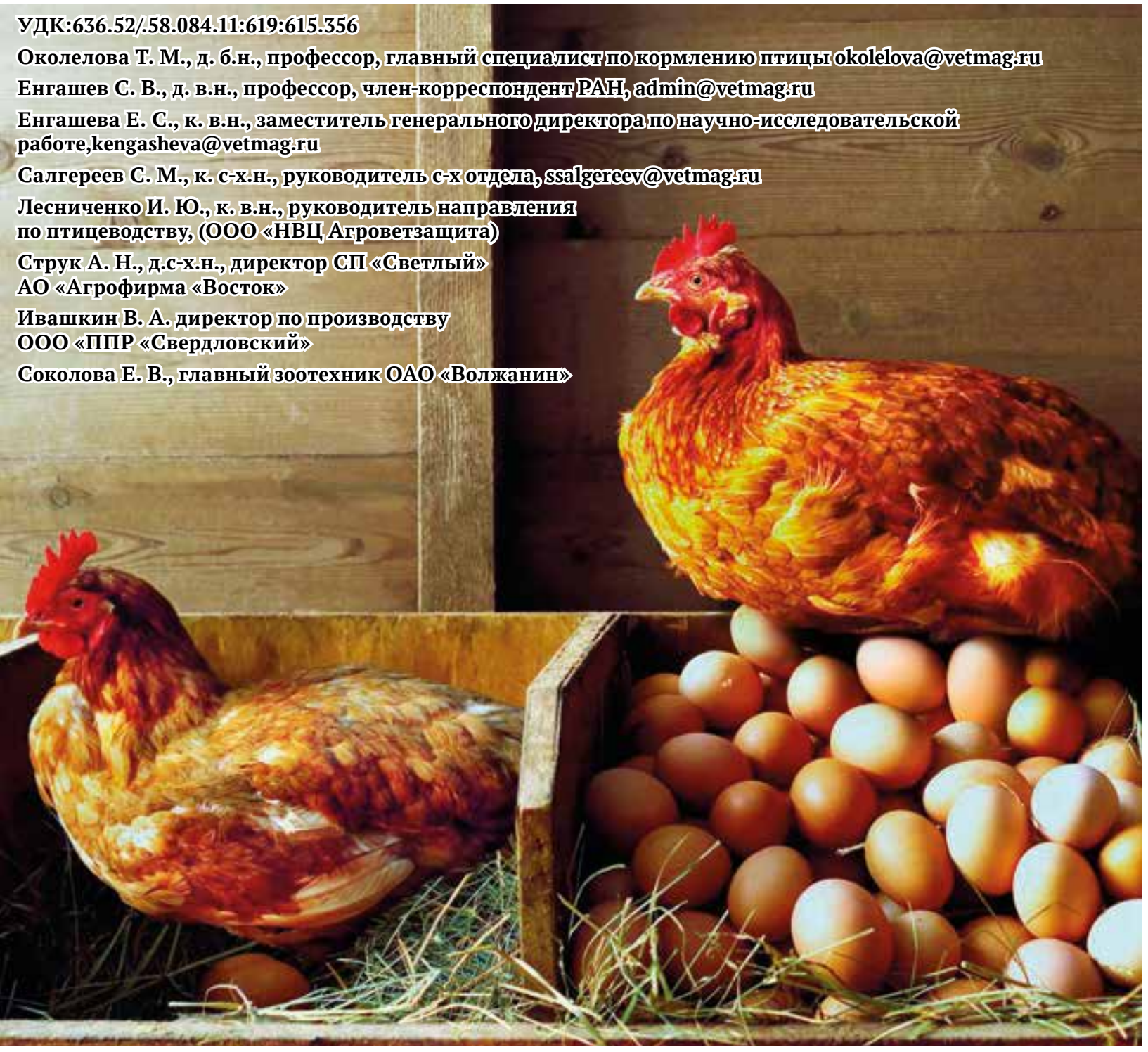

\title{
ЧТО ДАЕТ ДОПОЛНИТЕЛЬНАЯ ВЫПОЙКА ВИТАМИНА D ВЫСОКОПРОДУКТИВНЫМ НЕСУШКАМ?
}

\footnotetext{
Витамин $D_{3}$ играет большую роль в организме птицы, являясь индуктором синтеза кальций-связывающего белка, он способствует усвоению и отложению кальция в костях, скорлупе, регулирует обмен фосфора, магния, белков и углеводов, стимулирует окислительно-восстановительные процессы. К недостатку витамина $D_{3}$ особенно чувствительны высокопродуктивные несушки и интенсивно растущий молодняк на откорме $(3,5,8)$.
}

Y несушек дефицит витамина $\mathrm{D}_{3}$ в первую очередь отрицательно сказывается на качестве скорлупы. Дефицит витамина $\mathrm{D}_{3}$ в рационах племенной птицы в период яйцекладки является одним из факторов, угнетающих развитие эмбриона в оплодотворенных яйцах и резко снижающих его способности к вылуплению по причине плохого окостенения клюва. Цыплята, вылупившиеся из таких яиц, как правило, имеют слабый костяк уже в суточном возрасте (8-10). В последние годы D-витаминная недостаточность у птицы отмечается даже при его введении в рацион, например, когда в премиксы для птицы включают вместо витамина $\mathrm{D}_{3}$ физиологически менее активный $\mathrm{D}_{2}$, или используется препараты витамина $D_{3}$ с низкой биологической доступностью. Дефицит витамина $D_{3}$ может возникать при плохой гранулометрии комбикормов, низкой общей их питательности, при нарушениях в системе кормораздачи, а также под влиянием причин, приводящих к заболеваниям печени и почек, органов в которых происходит образование физиологически активных метаболитов, включая 1,25 диоксихолекальциферол (7). В жаркое время года, когда снижается потребление кормов и увеличивается потребление воды, также 
ухудшаются показатели минерального обмена, прежде всего у взрослой птицы, что проявляется в повышении боя и насечки яиц. Характерным признаком продолжительной недостаточности витамина $\mathrm{D}_{3}$ у молодняка является рахит, а у взрослой птицы остеопороз. Переуплотненная посадка при недостаточном фронте кормления и поения птицы приводит к расслоению поголовья по живой массе по причине недостаточного потребления комбикормов, сбалансированных по комплексу питательных и биологически активных веществ, включая витамины (2-4). Все это заставляет специалистов периодически выпаивать птице витаминные комплексы в водорастворимой форме. Как правило, такие комплексы содержат либо 3-4 витамина, либо все 14 витаминов, есть препараты, содержащие кроме витаминов, микроэлементы и аминокислоты. Однако чем больше компонентов в составе препарата, тем ниже концентрация действующих веществ и тем сложнее добиться их хорошей растворимости в воде. Объемный расход препаратов с низкой концентрацией действующих веществ всегда выше, чем более концентрированных растворов, а это дополнительные транспортные и прочие накладные расходы. Кроме того поступление остальных витаминов и прочих компонентов, содержащихся в применяемых препаратах, не всегда является необходимым, или они даются в очень низких концентрациях, которые сложно проконтролировать при анализе. В связи с изложенным, компания АВЗ разработала и предлагает производству водорастворимую форму витамина $\mathrm{D}_{3}$, которая предназначена для применения в качестве «скорой помощи» при проблемах с качеством скорлупы и костяка у птицы. Предлагаемый препарат в качестве действующего вещества содержит в 1 мл 15000ME витамина $\mathrm{D}_{3}$.

Цель работы: изучить влияние дополнительной выпойки витамина $\mathrm{D}_{3}$ на качество скорлупы, костяка и зоотехнические показатели племенной птицы.

\section{Материалы и методы.}

Работу по изучению эффективности дополнительной выпойки водорастворимой формы витамина $\mathrm{D}_{3}$ проводили параллельно в различных регионах и климатических зонах на племенной яичной птице трех кроссов в передовых хозяйствах по следующим схемам:

В условиях птицефабрики ОАО «Волжанин» (Ярославская область) с использованием кросса Ломан коричневый в первой группе кур с поголовьем 17520 голов на начало опыта в возрасте 280 дней (первая фаза продуктивности) витамин $D_{3}$ выпаивали три дня подряд один раз в месяц в течение 3-х месяцев из расчета 100 мл. на 1000 л. воды.

Во второй группе кур с поголовьем 17600 голов на начало опыта в возрасте 162 дня (первая фаза продуктивности) витамин $\mathrm{D}_{3}$ выпаивали три дня подряд два раза в месяц в течение 3-х месяцев из расчета 100 мл. на 1000 л. воды.

В третьей группе кур с поголовьем птицы 20930 голов на начало опыта в возрасте 442 дня (старая птица) витамин $D_{3}$ выпаивали еженедельно по одному дню в неделю в течение 3-х месяцев.

В ППР Свердловский (Свердловская область) первой группе кур с поголовьем 21400 голов кросса Декалб белый в возрасте 308 дней (вторая фаза продуктивности) витамин $D_{3}$ выпаивали один раз в месяц три дня подряд из расчета 100 мл. на 1000 л. воды в течение 3-х месяцев.

Во второй группе кур с поголовьем 22676 голов кросса Декалб белый в возрасте 196 дней (первая фаза продуктивности) витамин $D_{3}$ выпаивали по три дня подряд два раза в месяц из расчета 100 мл. на 1000 л. воды в течение трех месяцев.

В третьей группе кур с поголовьем 20717 голов кросса Хайсекс коричневый в возрасте 224 дня (первая фаза продуктивности) витамин $\mathrm{D}_{3}$ выпаивали еженедельно по одному дню в неделю из расчета 100 мл. на 1000 л. воды в течение 3-х месяцев.

В Агрофирме Восток АО СП «Светлый» (Волгоградская область) в первой группе кур с поголовьем 24840 голов кросса Хайсекс коричневый в возрасте 206 дней (первая фаза продуктивности) выпойку витамина $\mathrm{D}_{3}$ проводили один день в неделю еженедельно из расчета 100 мл. на 1000 л. воды в течение трех месяцев.

Во второй группе кур с поголовьем 26077 голов кросса Хайсекс браун в возрасте 342 дня на начало опыта выпойку препарата проводили два раза в месяц по три дня подряд из расчета 100 мл. препарата на 1000 л. воды в течение трех месяцев.

В опытах учитывали продуктивность птицы, сохранность поголовья, процент боя и насечки яиц, содержание золы в костях, толщину скорлупы, результаты инкубации яиц. Во всех опытах в экспериментальные группы брали по птичнику, поэтому изза разной их вместимости и разное поголовье кур в группах, однако оно вполне достаточно для объективной оценки эффективности применения препарата.

Результаты исследований и обсуждение

Результаты испытаний препарата в ОАО «Волжанин» показали, что в первой группе кур, прошедшей пик продуктивности яйценоскость планомерно снижалась, но за счет выпойки витамина она была за период опыта на 2,0\% выше плановых показателей и составляла $86 \%$ против $84 \%$ по плану. Сохранность поголовья за период опыта в среднем составила 99,24\% против 99,1\% на начало опыта. Количество насечки и нестандартного яйца снизилось за 3 месяца и в сумме составило 2,7\% против $3,0 \%$ на начало опыта, когда птица была моложе и яйцо было мельче. Толщина скорлупы при этом составила 0,390мм против 0,389мм на начало опыта. По итогам убоя птицы за время опыта содержание кальция в костях повысилось и составило $22,21 \%$ против $18,8 \%$ на начало опыта. Содержание фосфора в костях кур до выпойки препарата составляло 10,8\%, а в конце опыта $-11,5 \%$. Содержание витамина А в яйце за период опыта составило 8,5 мкг/г, против 7,5 мкг/г до начала опыта. Уровень каротиноидов в инкубационном яйце за период опыта составил 25,43мкг/г против 22,63 мкг/г до начала опыта. Таким образом, дополнительная выпойка витамина в течение трех дней подряд один раз в месяц улучшала показатели минерального обмена, качество скорлупы и снижало выход насечки и нестандартных яиц у стареющей птицы, обеспечивая при этом продуктивность кур выше плановых показателей и высокое качество инкубационных яиц.

Во второй группе кур, выходивших на пик продуктивности, при выпойке витамина два раза в месяц по три дня подряд яйценоскость за период опыта повысилась до 98,17\%, против $90,81 \%$ на начало опыта. При этом процент насечки яиц через месяц снизился до $1,11 \%$ против $1,71 \%$ на начало опыта, а в конце опыта насечка составила 1,03\%, что в 1,7 раза меньше, чем до приема препарата. И это при рекордно высокой продуктивности кур (98,17\%). Количество нестандартных яиц непригодных для инкубации до начала опыта составляло $8,25 \%$, а в конце опыта оно снизилось до $1,06 \%$, т.е. в 8 раз. Толщина скорлупы за период опыта повысилась и составила 0,365мм, против 0,355мм на начало опыта. Содержа- 
ние кальция в костях за период опыта после выпойки препарата повысилось до 22,4\% против 22,0\% на начало опыта, несмотря на большой вынос кальция с яйцом. Сохранность поголовья на начало опыта составляла 99,25\%, а в конце опыта 99,41\%. Анализ качества инкубационных яиц показал, что профилактическая выпойка витамина $\mathrm{D}_{3}$ не сказывалась отрицательно на содержании каротиноидов и витамина А в яйце, уровень которых был 23,51-28,69мкг/г и 8,52-8,75мкг/г соответственно до и после применения препарата. Таким образом, двукратная выпойка препарата по три дня подряд в месяц позволяет при выходе на пик продуктивности существенно повысить яйценоскость кур, сократив при этом количество нестандартных яиц в 8 раз и насечку яиц в 1,7 раза. При этом улучшается минерализация костяка толщина скорлупы яиц и общая сохранность птицы.

В третьей группе кур опыт проведен на старой птице с целью продления срока ее использования за счет еженедельной выпойки препарата в течение одного дня на протяжении трех месяцев. За период опыта яйценоскость птицы повысилась на 6,11\% с 73,43\% на начало опыта, до 79,54\% на конец испытаний. Сохранность поголовья была в конце опыта 97,3\% против 97,4\% в начале опыта. Насечка и нестандартное яйцо в сумме в начале опыта составили 7,21\%, в том числе насечка - 2,19\%. Через месяц опыта количество нестандартных яиц и насечки составило 6,46\%, в том числе насечки было 2,33\%. В конце опыта количество нестандартных яиц и насечки в сумме снизилось до 4,87\%. При этом насечка составила 2,61\%, хотя продуктивность птицы за это время повысилась существенно. За счет повышения продуктивности птицы в конце ее эксплуатации и снижения процента яиц не пригодных для инкубации повысился выход инкубационных яиц. При убое содержание кальция в костях у переярой птицы было в пределах нормы и составило 20,8\% против 21,6\% на начало опыта. Толщина скорлупы также была в пределах нормы 0,395-0,390мм. Содержание витамина А и каротиноидов в яйце в начале опыта было 7,5 мкг/г и 27,06 мкг/г соответственно, а в конце опыта 8,9 мкг/г и 25,15 мкг/г и это несмотря на повышение продуктивности кур и больший вынос биологически активных веществ из организма. Таким образом, еженедельная выпойка витамина по одному дню в неделю позволяет повысить продуктивность кур и продлить срок использования переярой птицы. При этом количество яиц непригодных для инкубации снизилось в 1,5 раза. Дополнительная профилактическая выпойка витамина $D_{3}$ не оказала отрицательного влияния на депонировании витамина А и каротиноидов в инкубационном яйце.

В ППР Свердловский в ходе испытаний в первой группе кур при выпойке препарата один раз в месяц в течение трех дней подряд за период опыта выход племенной продукции составил 95,74-95,98\%. Отход птицы по причине слабости костяка, в процентах от общего падежа, снизился с 14,28\% в начале опыта до 4,5\% в конце, т.е. патология уменьшилась более чем в 3 раза. При анализе качества яиц установлено, что средняя масса яиц на начало опыта составила 57,23 г. при массе и толщине скорлупы 5,87 г. и 0,350 мм. соответственно. К концу опыта масса яиц повысилась и составила 59,93 г. при массе и толщине скорлупы 5,98 г. и 0,360 мм. соответственно. Однако, несмотря на повышение массы яиц, процент боя и насечки снизился с 3,25\% до 1,31\% или в 2,5 раза. Анализ качества яиц на содержание витамина А и ка- ротиноидов показал, что в начале опыта их концентрация в желтке составляла 7,39 мкг/г и 25,74 мкг/г, а в конце опыта - 8,21 мкг/г и 25,86 мкг/г соответственно. Данные по содержанию витамина А и каротиноидов в желтке также свидетельствуют о том, что дополнительная кратковременная выпойка витамина $\mathrm{D}_{3}$ не создает проблемы дисбаланса витаминов в организме и не сказывается отрицательно на их депонировании в яйце. При этом, несмотря на возрастное увеличение массы яиц, процент боя и насечки снижается. Кроме того снижается отход птицы по причине клеточной усталости, что важно не только для второй фазы продуктивности племенных кур, но особенно для промышленных несушек более длительного использования.

Трехдневная выпойка препарата два раза в месяц во второй группе кур обеспечила выход племенной продукции к концу опыта до 97,58\% против 94,16\% на начало опыта. При этом процент боя и насечки яиц у молодой птицы в начале опыта составил 2,1\%, а в конце - $1,0 \%$, т.е. был в два раза ниже. Отход птицы по причине слабости костяка в процентах от общего падежа в начале опыта составлял 9,24\%, а в конце опыта он снизился до 2,38\%, т.е в 3,9 раза. Анализ качества яиц показал, что средняя их масса в начале опыта была 55,99 г. при массе и толщине скорлупы 5,94 г и 0,350 мм. соответственно. В конце опыта эти показатели были на уровне 59,7 г., 5,81 г. и 0,350 мм. соответственно. Содержание витамина А и каротиноидов в яйце в начале опыта было на уровне 7,14 мкг/г. и 19, 92 мкг/г, а в конце - 7,9 и 29,14 мкг/г соответственно. Таким образом, двукратная выпойка препарата в месяц по три дня подряд также способствовала снижению отхода птицы по причине слабости костяка и снижению боя и насечки яиц до 1,0\%

Еженедельная однодневная выпойка препарата в третьей группе кур обеспечила выход племенной продукции к концу опыта до 93,59\% против 92,9\% в начале опыта при бое и насечке яиц 2,89\% и 3,19\% соответственно. При этом отход птицы по причине слабости костяка в начале опыта составил 13,08\% от общего падежа, а в конце опыта он снизился до 7,23\% или в 1,8 раза от общего падежа. Анализ качества яиц показал, что их масса в начале опыта была 60,01г при массе и толщине скорлупы 6,18 г. и 0,360 мм. В конце опыта эти показатели были на уровне 63,37 г., 6,27 г., и 0,370 мм. соответственно. Уровень витамина А и каратиноидов в желтке в начале опыта был 7,73 мкг/г и 23,41 мкг/г, а в конце -7,37 мкг/г и 28,92 мкг/г соответственно. Еженедельная однодневная выпойка препарата также улучшала показатели минерального обмена, что положительно сказалось на снижении отхода птицы по причине слабости костяка и уменьшении боя и насечки яиц.

Результаты испытаний витамина $D_{3}$ в Агрофирме Восток АО СП «Светлый» показали, что в первой группе, где птица получала дополнительно витамин еженедельно по одному дню, средняя интенсивность яйценоскости за период опыта составила 94,79\% против 91,17\% в начале опыта. Отход птицы за 100 дней опыта составил 255 голов, против 559 голов за аналогичный период в контроле. По результатам инкубации яиц после выпойки витамина курам процент вывода цыплят составил 82,22\% против 78,28\% до применения препарата. Повышение процента вывода цыплят составило 3,94\%. При анализе отходов инкубации отмечено снижение процента неоплодотворенных яиц, кровяного кольца, замерших и задохликов. Что связано как с состоянием костяка у птицы, так и с каче- 
ством скорлупы, зависящими от обеспеченности птицы дитамином $D_{3}$.

Во второй группе, где птица была старше и дополнительно получала витамин $D_{3}$ по три дня подряд, средняя интенсивность яйценоскости за опыт составила 90,42\% против 85,94\% до начала эксперимента. При этом отход птицы за период опыта составил 285 голов, против 380 голов за аналогичный период в контроле. Среди причин падежа в опытных группах было меньше кур с нарушениями минерального обмена.

По результатам инкубации процент вывода цыплят из яиц от кур, получавших дополнительно витамин, составил 81,5\% против 73,3\% в контроле. Разница была 8,2\%, что вполне естественно для птицы старшего возраста. Таким образом, дополнитель- ная выпойка витамина $\mathrm{D}_{3}$ способствует повышению продуктивности птицы в разные возрастные периоды на 3,62-4,48\%, процента вывода цыплят на 3,94$8,25 \%$ и снижает отход птицы в 2,2-1,3 раза.

\section{Заключение}

Как показали исследования, дополнительная выпойка витамина Д несушкам разного возраста и уровня продуктивности обеспечивала не только повышение продуктивности, но и способствовала улучшению минерализации костяка и качества скорлупы, что выражалось в снижении падежа птицы, боя и насечки яиц и повышении вывода цыплят. Кратность и продолжительность выпойки препарата в каждом конкретном случае определяют специалисты хозяйства. Норма расхода составляет 100 мл. раствора витамина Д на тонну воды.

\section{ЛИТЕРАТУРА}

1. Енгашев С. В., Околелова Т. М., Салгереев С. М., Пашкин А. В. Причины клеточной усталости несушек. Птицеводство, - № 9. - 2017. - С. 7-11.

2. Околелова Т. М., Кулаков А. В., Молоскин С. А., Грачев Д. М. Актуальные проблемы применения биологически активных веществ и производства премиксов. Сергиев Посад. - 2002. - 283с.

3. Околелова Т. М., Румянцев С. В., Кулаков А. В. Корма и биологически активные добавки для птицы. М. - Колос. -1999. -96с.

4. Околелова Т.М. Кормление сельскохозяйственной птицы. М. ВО Агропромиздат. -1987. -112с.

5. Околелова Т. М. Кормление сельскохозяйственной птицы. Сергиев Посад.1996. - 168с.

6. Подобед Л. В., Околелова Т. М. Диетопрофилактика кормовых и технологических нарушений в интенсивном птицеводстве. Одесса. Печатный дом. - 2010. - 298с.

7. Околелова Т. М. Что нужно знать о качестве сырья и биологически активных добавках для птицы? Сергиев Посад. - 2016. - 280с. 8. Подобед Л.И., Фисинин В.И., Егоров И.А., Околелова Т.М. Кормовые и технологические нарушения в птицеводстве. Одесса. «Акватория». - 2013. - 496с.

9. Околелова Т. М., Шарипов Р.И., Актуальность применения биологически активных веществ и премиксов в птицеводстве. Астана. -2017 . $-220 c$

10. Околелова Т.М., Енгашев С. В., Салгереев С. М. Клеточная усталость несушек: причины и профилактика. Ветеринария. 2017. - № 11. - С. $15-19$

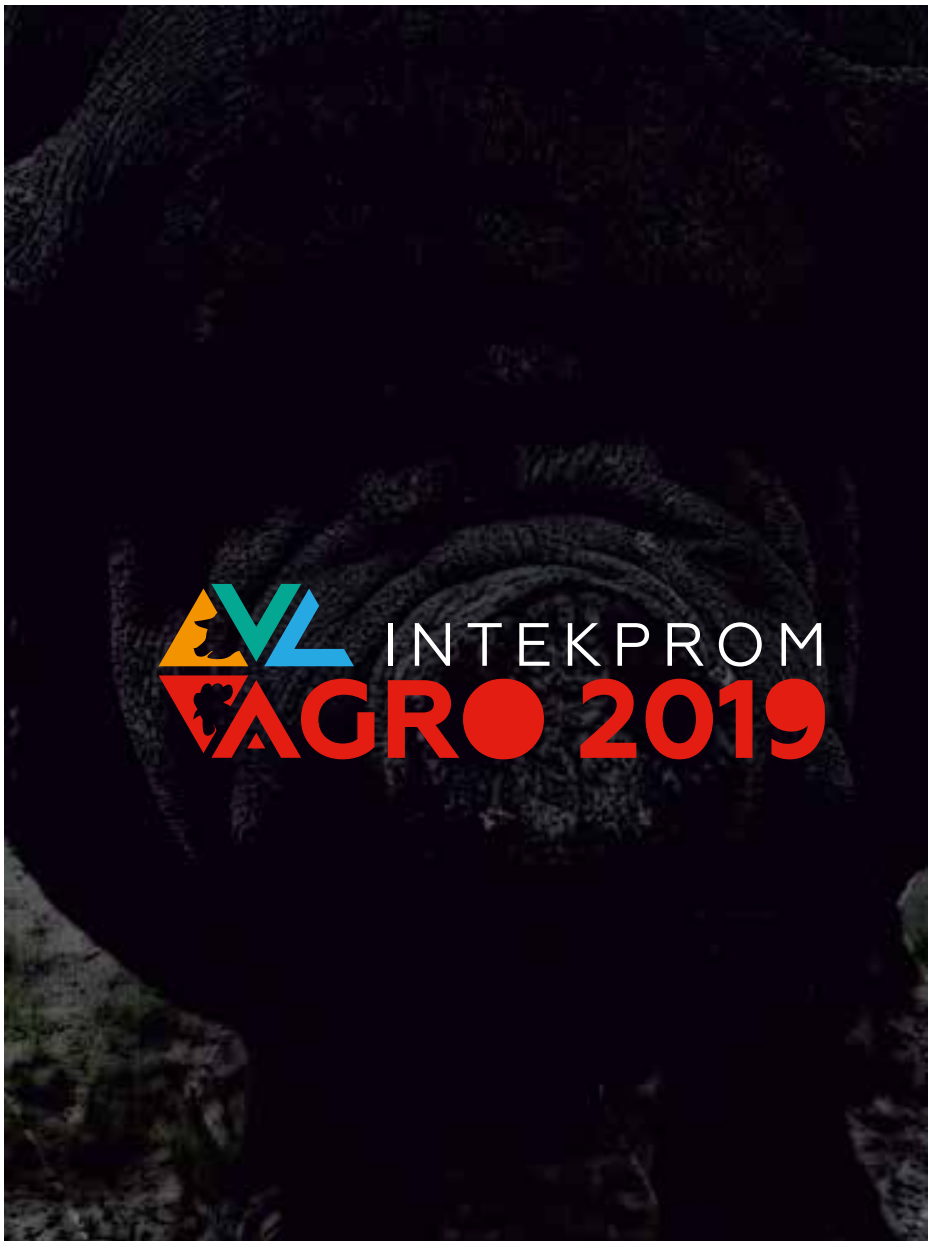

Российская конференция «Повышение эффективности предприятий птицеводства и свиноводства 2019,

Дата проведения: 24 апреля 2019г.

Стратегические темы конференции: Опыт внедрения бережливого производства на предприятиях птицеводства и свиноводства и достигнутые результаты

Опыт внедрения системы энергоменеджмента на предприятиях птицеводства и свиноводства и достигнутые результаты

Оптимизация инраструктуры предприятий Опыт производства продукции с высокой добавленной стоимостью

Развитие экспорта продукции: меры, зависящие от предприятия

Участники: более 200 человек

Представители птицефабрик

Представители свиноводческих хозяйств

Поставщики оборудования и технологических решений

Более подробная информация:

intekprom.ru/agro2019

+7 (495) 777-96-71

Для участия необходима предварительная регистрация! 